\title{
A Novel Driving Method for Switched Reluctance Motor with Standard Full Bridge Inverter
}

\author{
Haitao Sun, Student Member, IEEE, Ali Farzan Moghaddam, Peter Sergeant, Member, IEEE and Alex \\ Van den Bossche, Senior Member, IEEE ${ }^{1}$
}

\begin{abstract}
This paper proposes a new driving method for a switched reluctance motor (SRM) by using a standard full bridge. The windings in the SRM are connected in series to build a ring structure, where a controllable DC source is inserted. Based on the new structure, the theoretical analysis and calculation are made to determine the control parameters. Besides three-phase SRM, the new idea can also be applied to the SRMs with four and five phases. The new driving method is compared with the conventional method by simulation. The results show that with the new method, the ripple of torque and speed in the SRM reduces. The influence of the proposed method on the power rating and losses is then analyzed. The validation is also made to verify the application of the new method and the difference between the conventional driving method and the proposed method. The measured results match the simulated results well.
\end{abstract}

Index Terms-Switched Reluctance Motor, Motor Drives, Machine Control, Bridge Circuits, Current Measurement

\section{INTRODUCTION}

It is commonly known that a switched reluctance motor (SRM) has to be driven by the asymmetric H-bridges. Even with the different number of phase, in an asymmetric H-bridge circuit, two diode transistor legs are required for every phase winding [1] . A three-phase SRM can be taken as an example (Fig. 1): 6 diode transistor legs are required in the traditional topology with a minimum number of 8 contacts ( 2 for supplies and 6 for outputs). At the same time, because the asymmetric $\mathrm{H}$-bridges are usually not made in mass production, the IGBT with the external diode increases the cost of the production.

Fig. 1. Standard asymmetric H-bridge topology for SRM

Because of the specific structure, the asymmetric H-bridge circuit cannot be applied in the driving systems for induction

\footnotetext{
${ }^{1}$ This work was supported in part by the China Scholarship Council under Grant 201606930007

H. Sun, A. F. Moghaddam and A. V. Bossche is with the Department of Electrical Energy, Metals, Mechanical Constructions and Systems, Ghent University, Gent 9052, Belgium (e-mail: haitao.sun@ugent.be; ali.farzanmoghaddam@ugent.be; alex.vandenbossche@ugent.be).
}

motors and synchronous motors (PM or excited), which causes the asymmetric H-bridges not to be mass-produced. The full bridge inverter is another topology of power converter considered by many researchers for SRM. Instead of external diodes, a full bridge circuit uses MOSFETs with internal diodes [2], which reduces its production costs because the full bridge circuit can also be applied in driving induction motors and synchronous motors. A three-phase SRM can also be taken as an example (Fig. 2). Compared to Fig. 1, the three-phase full bridge inverter requires only 5 contacts ( 2 for supplies and 3 for outputs) [3], which reduced the complexity.

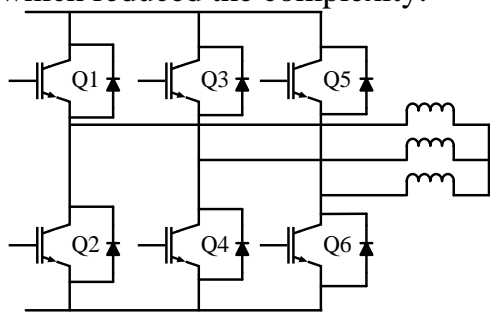

Fig. 2. Conventional 3 phase full bridge inverter for BLDC

The following paragraphs give an overview of the literature studies that try to drive the SRM via the full bridge topology.

A type of mutually coupled SRM is mentioned in [4] that changes the direction of the neighboring phase winding, so that with a standard 3-phase inverter it can generate positive EM torque. It is a type of synchronous reluctance machines, the main idea for operation is the rotating magnetic field, which does not exist in a conventional SRM.

[5] designs an integrated multilevel converter for SRM drive, it develops a conventional asymmetrical half-bridge converter with a front-end circuit, this circuit integrates the generator and battery bank in the drive system with only two IGBTs and two diodes without adding extra capacitors and inductors.

The authors of [6] [7] describe a field regulated reluctance machine, in which the windings are divided into two groups at the same time: excitation windings and armature windings, for a particular winding, it is dependent on the rotor position. During the period when the coils of a particular winding are located under the pole faces, the current flowing in them corresponds to and is controlled as the equivalent of an armature

P. Sergeant is with the Department of Electrical Energy, Metals, Mechanical Constructions and Systems, Ghent University, Gent 9052, Belgium and also with EEDT - Flanders Make, the strategic research centre for the manufacturing industry, Gaston Geenslaan 8, 3001 Leuven, Belgium (e-mail: peter.sergeant@ugent.be) 
current of a dc motor. While the coils of a winding are located in the inter-pole space, the current flowing in them corresponds to and is controlled as field current. Because of this type of operation mode, this motor can be driven by a standard inverter.

[8] proposes a type of variable reluctance Vernier motor that can be driven by a 3-phase inverter. This type of motor has slots and a distributed winding just like the stator of an ordinary polyphase induction motor. The rotor is a slotted iron core without winding. The rotor speed has a proportional relationship with the speed of the rotating field.

A new toroidal wound switched SRM with a single continuous multi-tapped winding is presented in [9] . This type of SRM can be driven by two 3-phase standard inverters, where the continuous winding is defined as the winding that is mechanically or electrically uninterrupted and that may be constructed of individual windings joined in series, so that with a 12-switch inverter that can supply bipolar coil currents, the new SRM can be driven.

[10] explains the principle of controlling the IGBT-inverter switches that supply one phase power motor branch of the SRM, this is also a driving method similar to [5] , which was described as bipolar excitation method.

A new self-commutating low-speed reluctance motor is designed by [11] , of which each phase has two parallel halfphase windings, between the source and the stator windings, there is a static inverter consisting of six diodes, it is constructed using five inverter legs and two parallel brake legs in the two three-phase IGBT power modules, the conventional power converter can correspond to the new circuits. With this, the motor can be driven by a normal 3-phase inverter.

To be concluded, all the new designs mentioned above are focused on changing the topology of the motor itself or changing the structure of the driving circuit. However, without changing the motor structure, all the mentioned designs cannot be applied to the general SRMs that have different phases.

Without changing the topology of the motor itself, this paper proposes a new drive structure for SRM, which can be applied in the conventional SRMs even with different phases. By using a ring structure, the proposed method makes it possible to drive a SRM with the full bridge circuit.

\section{THEORETICAL ANALYSIS OF THE PROPOSED TOPOLOGY}

\section{A. Topology}

The proposed topology is described in Fig. 3, taking a threephase SRM as an example. The three phase windings are formed with a delta structure, between two neighboring windings $\left(\mathrm{R}_{1}\right.$ and $\left.\mathrm{R}_{3}\right)$, an additional $\mathrm{DC}$ source is inserted and connected in series to build a ring structure [12] .

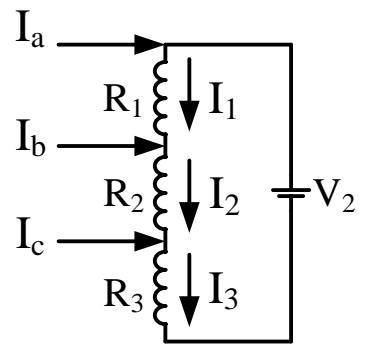

Fig. 3. Concept of the ring structure to generate circulating current
Replaced the DC source with a controlled DC voltage source, the full topology of the proposed method is shown in Fig. 4. The IGBTs Q1-Q6 control the leg current for driving the SRM, of which the reference value is described as $I_{R C l}$. The half-bridge circuit $(\mathrm{C} 1, \mathrm{C} 2, \mathrm{Q} 7, \mathrm{Q} 8)$ controls the circulating current in the ring structure, the circulating current helps to improve the fundamental winding current to be higher than $0 \mathrm{~A}$, of which the reference value is $I_{R C 2}$.

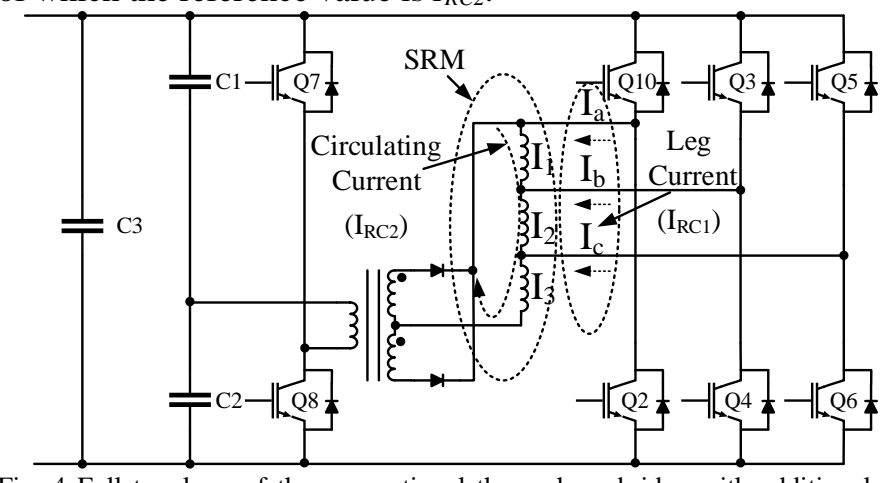

Fig. 4 Full topology of the conventional three phase bridge with additional power supply

\section{B. Operating principle}

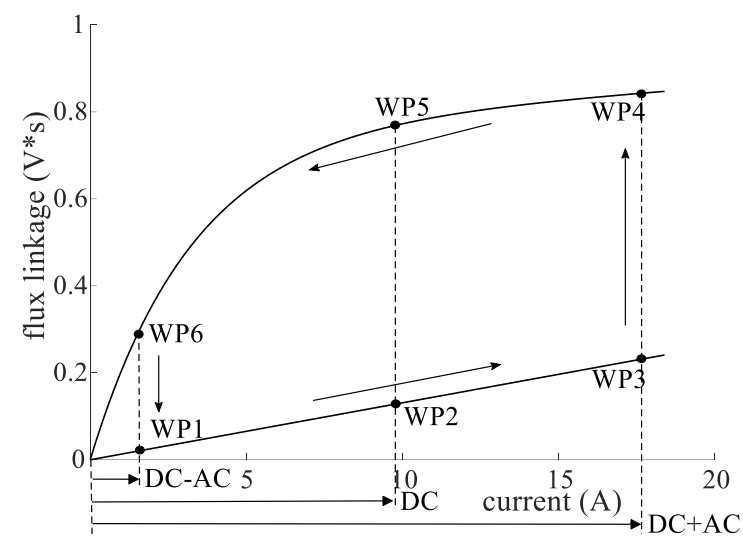

Fig. 5 The flux linkage-current diagram of the SRM

Fig. 5 shows the working area of the SRM driven by the new method, where the DC means the circulating current in the ring structure, $\mathrm{AC}$ means the $\mathrm{AC}$ currents in the inverter legs, and the current at every working point (WP1-WP6) means the winding current.

At the unaligned position, the leg current increases from a maximum negative value, while the well-chosen circulating current keeps the winding current positive. As the working point moves from WP1 to WP2, the leg current increases to zero, where the winding current is equal to the circulating current. With the leg current increasing, the working point moves from WP2 to WP3. The stator moves to the aligned position, where the leg current achieves its maximum positive value [13] .

At the aligned position, the working point moves from WP3 to WP4. Then with the motion of the rotor, the leg current decreases, and the working point moves from WP4 to WP5. At WP5, the leg current decreases to zero again. When leg current decreases to the maximum negative value, the working point moves from WP5 to WP6. At the same time, the winding current keeps positive because of the circulating current. 
To drive a SRM, the direction of the winding current has to retain the same during the operating period [14] . Based on the principle described above, the ring structure makes it possible for the full bridge driving circuit to drive a SRM. Based on the operational principle of SRM, if the two-direction rotation is required, the excitation sequence of the windings can be changed. If the waveform is shifted $180^{\circ}$, the torque is reversed.

\section{Calculation of the circulating current}

As is described in Fig. 6, the SRM provides the position signals and the value of the circulating current. The output of the motor data acquisition includes position signals and measured currents. The speed is calculated from the position signals. The circulating current is calculated from the winding current and leg currents, which are measured by three current sensors. The equation of the calculation of circulating current is shown in (6).

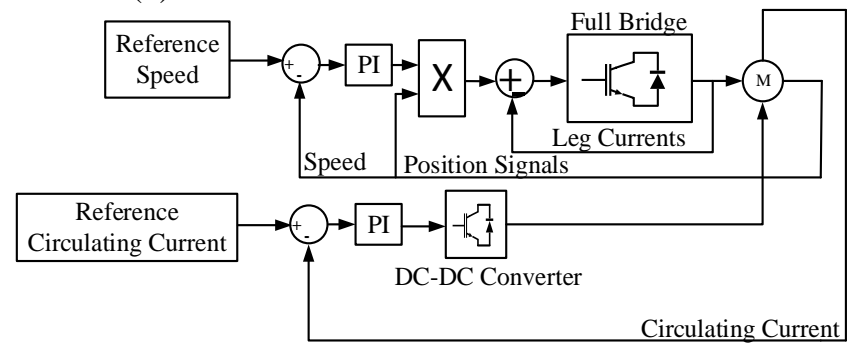

Fig. 6 The block diagram of the control strategy of the proposed system

By regulating the leg currents, the full-bridge circuit generates the excitation voltages for the SRM windings. After comparing with the reference circulating current, the circulating current is maintained by the half-bridge DC-DC converter, which is acted as the controllable voltage source.

Well-chosen reference values of leg current and circulating current can contribute to reducing unnecessary energy losses. Based on the conventional control strategy for the full bridge driving system, the leg current can be controlled based on the feedback position signals [15]. The circulating current has to be calculated by using the vector calculation.

We assume $I_{R C l}$ as the reference value for the leg current. Based on the block diagram of the control strategy of the proposed system (Fig. 6), it can be found that the leg currents are regulated by the full-bridge, which is controlled by the reference speed and the feedback position signals. The output of the multiplier in Fig. 6 is the reference value for the leg current $\left(I_{R C l}\right)$.

We assume $I_{R C 2}$ as the reference value for the leg current. Based on Fig. 3 and Fig. 4, the relationship of different type currents in the SRM can be formulated as follows:

$$
\overrightarrow{I_{R C 2}}=\frac{\overrightarrow{I_{1}}+\overrightarrow{I_{2}}+\overrightarrow{I_{3}}}{3}=\frac{3 \overrightarrow{I_{3}}+2 \overrightarrow{I_{a}}+\overrightarrow{I_{b}}}{3}
$$

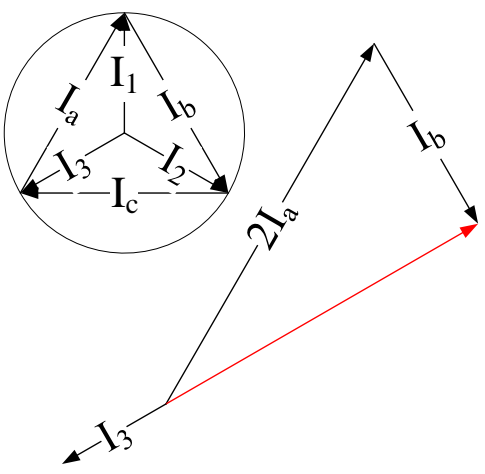

Fig. 7 The vector illustration of currents

From Fig. 7, it can be found that the direction of $I_{3}$ and $2 I_{a}+I_{b}$ are opposite, the relationship among the circulating current, leg current and winding current can be described as

$$
\left|\overrightarrow{I_{R C 2}}\right|=\left|\overrightarrow{I_{3}}\right|-\left|\frac{\sqrt{3}}{3} \overrightarrow{I_{R C 1}}\right|
$$

Because of

$$
\begin{gathered}
0 \leq\left|\vec{I}_{1}\right|=\left|\overrightarrow{I_{2}}\right|=\left|\overrightarrow{I_{3}}\right| \leq I_{\text {max }}, \\
0 \leq\left|\overrightarrow{I_{R C 2}}\right|+\left|\frac{\sqrt{3}}{3} \overrightarrow{I_{R C 1}}\right| \leq I_{\text {max }} \\
0 \leq\left|\overrightarrow{I_{R C 2}}\right| \leq I_{\text {max }}-\left|\frac{\sqrt{3}}{3} \overrightarrow{I_{R C 1}}\right|
\end{gathered}
$$

Where $I_{\max }$ is the maximum value of the winding current.

Based on (4) and (5), the reference value for the circulating current can be determined. With the well-calculated $I_{R C l}$ and $I_{R C 2}$, the winding current can be limited within the working area.

\section{VERSATILITY FOR THE SRMS WITH MORE PHASES}

The new driving topology can also be applied to the SRMs with different phases. To verify the versatility of the new method, the SRMs with four phases and five phases are analyzed by using the proposed method.

Fig. 8 shows a four-phase SRM with the windings connected in series, which form a ring structure. Between the windings $\mathrm{R}_{1}$ and $\mathrm{R}_{4}$, an additional DC source is inserted.

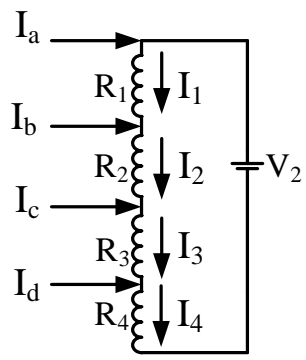

Fig. 8 Concept of the ring structure to generate circulating current in a 4 phase SRM

Based on the description above, the reference current for the leg current $\left(I_{a}, I_{b}, \ldots, I_{e}\right)$ is described as $I_{R C l}$, while the reference 
current for the circulating current is $I_{R C 2}$. The relationship among different type currents can be described as

$$
\overrightarrow{I_{R C 2}}=\frac{\overrightarrow{I_{1}}+\overrightarrow{I_{2}}+\overrightarrow{I_{3}}+\overrightarrow{I_{4}}}{4}=\frac{4 \overrightarrow{I_{4}}+3 \overrightarrow{I_{a}}+2 \overrightarrow{I_{b}}+\overrightarrow{I_{c}}}{4}
$$

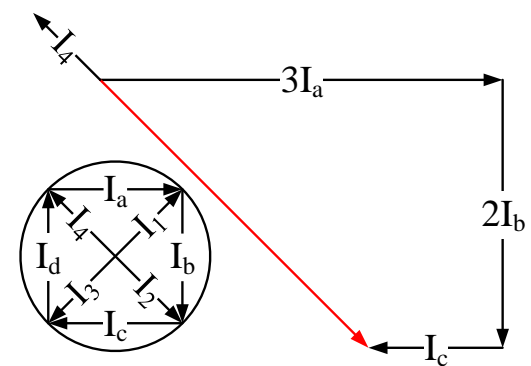

Fig. 9 The vector of the currents in a 4-phase SRM

As is shown in Fig. 9, the directions of $I_{4}$ and $3 I_{a}+2 I_{b}+I_{c}$ are opposite. The relationship among the circulating current, leg current and winding current can be described as

$$
\left|\overrightarrow{I_{R C 2}}\right|=\left|\overrightarrow{I_{4}}\right|-\left|\frac{\sqrt{2}}{2} \overrightarrow{I_{R C 1}}\right|
$$

Because of

$$
\begin{aligned}
& 0 \leq\left|\overrightarrow{I_{1}}\right|=\left|\overrightarrow{I_{2}}\right|=\left|\overrightarrow{I_{3}}\right|=\left|\overrightarrow{I_{4}}\right| \leq I_{\max }, \\
& 0 \leq\left|\overrightarrow{I_{R C 2}}\right|+\left|\frac{\sqrt{2}}{2} \overrightarrow{I_{R C 1}}\right| \leq I_{\max } \\
& 0 \leq\left|\overrightarrow{I_{R C 2}}\right| \leq I_{\max }-\left|\frac{\sqrt{2}}{2} \overrightarrow{I_{R C 1}}\right|
\end{aligned}
$$

It proves that the new method can be applied in the fourphase SRM theoretically.

The ring structure applied in five-phase SRM is shown in Fig. 10. The windings are connected in series and an extra DC source is inserted between the windings $R_{1}$ and $R_{5}$.

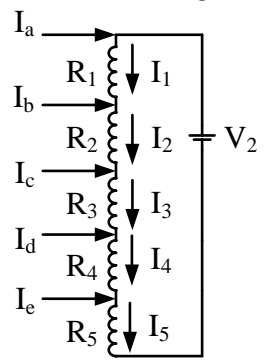

Fig. 10 Concept of the ring structure to generate circulating current in a 5-phase SRM

The vector relationship among the currents in Fig. 10 is described in Fig. 11. The relationship among different type currents can be formulated as

$$
\begin{aligned}
& \overrightarrow{I_{R C 2}}=\frac{\overrightarrow{I_{1}}+\overrightarrow{I_{2}}+\overrightarrow{I_{3}}+\overrightarrow{I_{4}}+\overrightarrow{I_{5}}}{5} \\
& =\frac{5 \overrightarrow{I_{5}}+4 \overrightarrow{I_{a}}+3 \overrightarrow{I_{b}}+2 \overrightarrow{I_{c}}+\overrightarrow{I_{d}}}{5}
\end{aligned}
$$

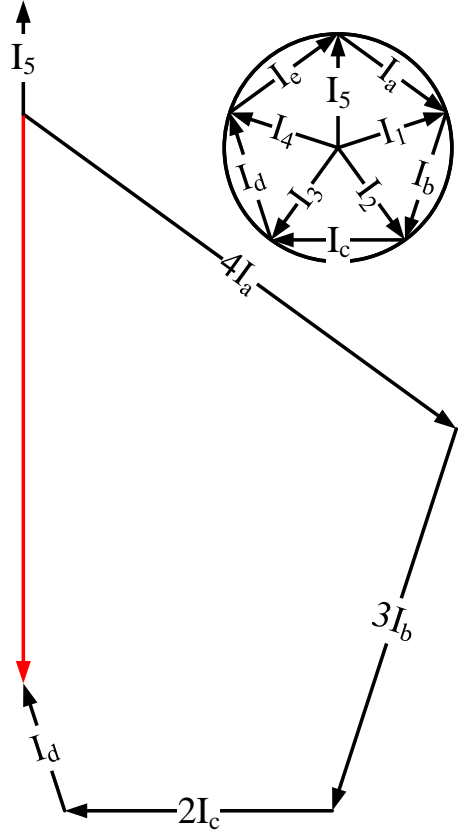

Fig. 11 The vector of the currents in 5-phase SRM

Again, it can be found that the directions of $I_{5}$ and $4 I_{a}+3 I_{b}+2 I_{c}+I_{d}$ are opposite, which makes it easy to calculate the reference currents.

Because of

$$
\begin{aligned}
0 \leq\left|\overrightarrow{I_{1}}\right|=\left|\overrightarrow{I_{2}}\right|=\left|\overrightarrow{I_{3}}\right|=\left|\overrightarrow{I_{4}}\right|=\left|\overrightarrow{I_{5}}\right| \leq I_{\max }, \\
0 \leq\left|\overrightarrow{I_{R C 2}}\right|+\left|\frac{\sqrt{18}}{5} \overrightarrow{I_{R C 1}}\right| \leq I_{\max } \\
0 \leq\left|\overrightarrow{I_{R C 2}}\right| \leq I_{\text {max }}-\left|\frac{\sqrt{18}}{5} \overrightarrow{I_{R C 1}}\right|
\end{aligned}
$$

The theoretical analysis above proves that the SRM with five-phase can be driven by the new method. According to the equations obtained, the SRMs with different phases can be driven by the full bridge driving system theoretically.

\section{COMPARISON BETWEEN DIFFERENT METHODS}

In order to test the new method by simulations, the SRM model with the structure $6 / 4$ is chosen as the driving target. The SRM driven by the conventional method is also described as the comparison.

The SRM tested has the characteristic described in Fig. 5. The excitation voltage is set with $200 \mathrm{~V}$. For the two types of control methods, we choose the reference speed as 1000rpm and the load as $6 \mathrm{~N}^{*} \mathrm{~m}$, the reference value of circulating current is $4.5 \mathrm{~A}$.

Fig. 12 shows the waveform of the winding currents in the SRM driven by the conventional method. 


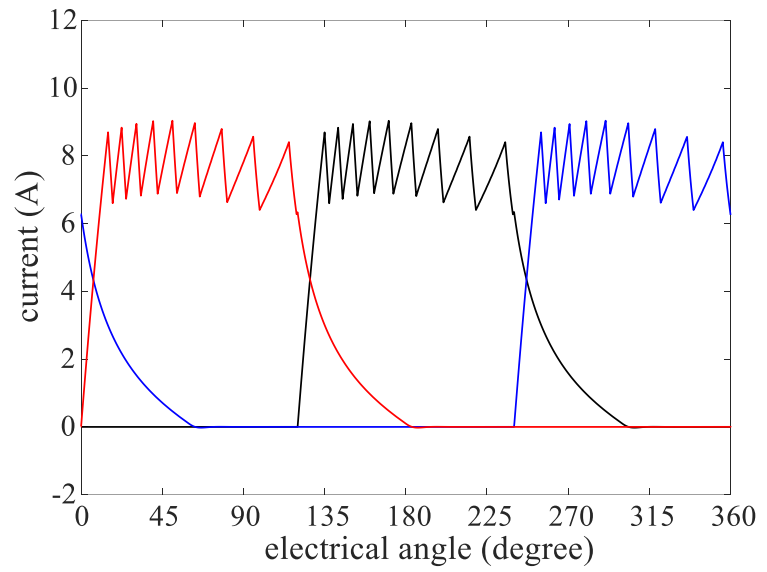

Fig. 12 The waveform of the winding currents in the 6/4 SRM driven by the conventional method

It can be found in Fig. 12 that the SRM driven by the conventional method generates the flat-top waveforms for winding currents [16] .

Fig. 13 describes the waveforms of the winding current of the SRM driven by the new method.

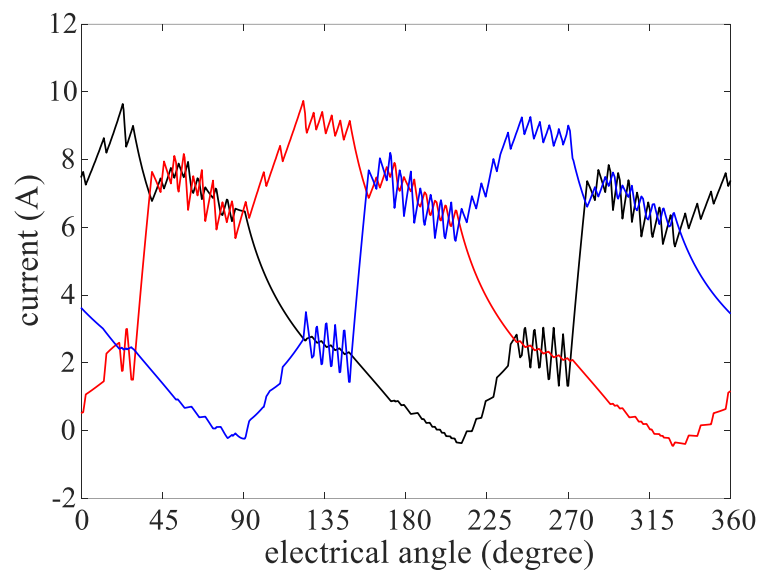

Fig. 13 The waveform of the winding currents in the 6/4 SRM driven by the new method

From Fig. 13, it can be seen that with a well-chosen reference value of the circulating current, the winding current in the SRM remains positive most of the time, which makes it possible to drive the SRM by using the ring structure.

In order to analyze the currents in the driving system, the leg currents in the full bridge circuit and the circulating current in the ring structure are shown in Fig. 14 and Fig. 15 respectively.

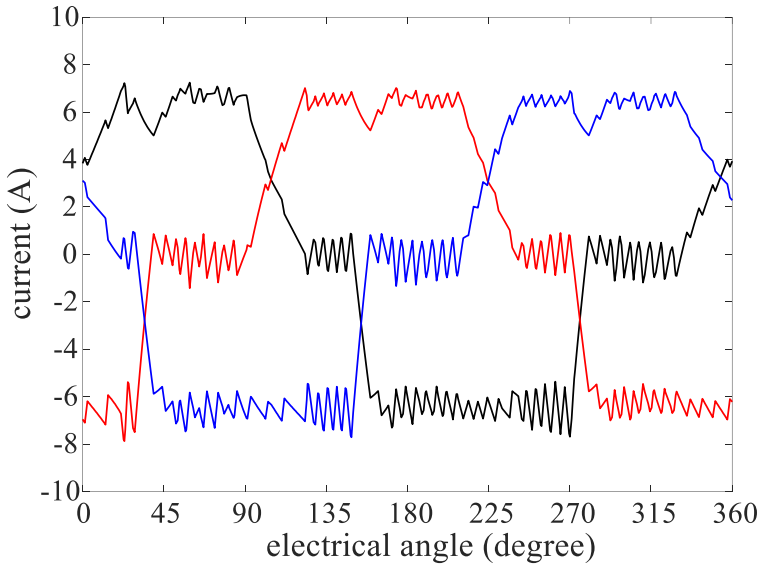

Fig. 14 The waveform of the leg currents in the 6/4 SRMs driven by the new method

Fig. 14 shows that the leg currents from the full bridge circuits have trapezoidal waveforms [17]. Because the circulating current is controlled by the PWM in the ring structure, the leg currents cannot be kept fully symmetrical.

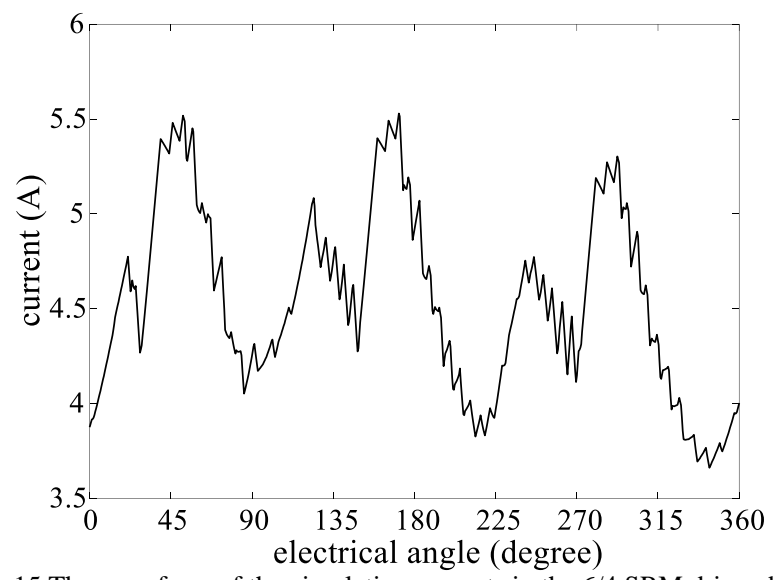

Fig. 15 The waveform of the circulating currents in the 6/4 SRM driven by the new method

Fig. 15 explains that with a well-calculated reference value, the circulating current can be kept relatively stable. From the waveform, it can also be found that the harmonic waves are existing in the circulating current. The reason is that the winding currents in the SRM have different phase angles, while the windings are connected in series. As a result, the circulating current has to contain the harmonic waves [18] . 


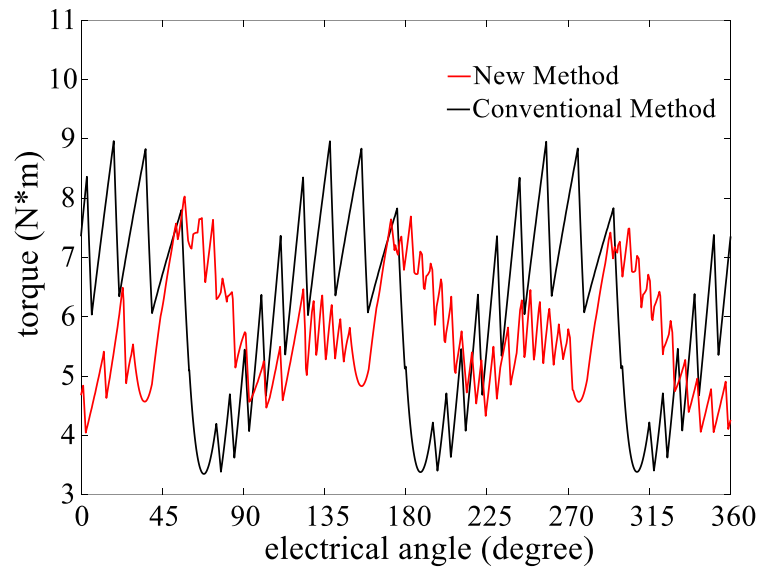

Fig. 16 The comparison of the torque in the 6/4 SRM driven by different methods

Fig. 16 describes the comparison of the torques between the two different driving methods. It can be found that the torque ripple of the new method is much lower than the ripple in the case of the conventional method: the peak-to-peak value of the torque ripple is $5.5 \mathrm{~N} * \mathrm{~m}$ in the conventional method, while in the new method, the value is $3.5 \mathrm{~N} * \mathrm{~m}$. It proves that compared to the conventional method and with a load of $6 \mathrm{~N}^{*} \mathrm{~m}$, the new method can reduce the peak-to-peak value of the low frequency torque ripple by $36.36 \%$.

Fig. 16 also shows that there are low frequency torque ripples in the new method.

The low frequency torque ripple is caused by the DC-DC converter structure (as is shown in Fig. 4 and Fig. 6). In the conventional method, there is no DC-DC converter inserted, and therefore the low frequency ripple does not appear in this method.

The reason for the low frequency ripple is the diodes in the secondary side of the DC-DC converter, as is shown in Fig. 4. When the winding current reaches zero, the current in the diodes in the secondary side of the DC-DC converter will also be zero. A sudden positive voltage appears at the output of the DC-DC converter, which causes the torque change. This torque change is manifested as the low frequency torque ripple, as is shown in Fig. 16.

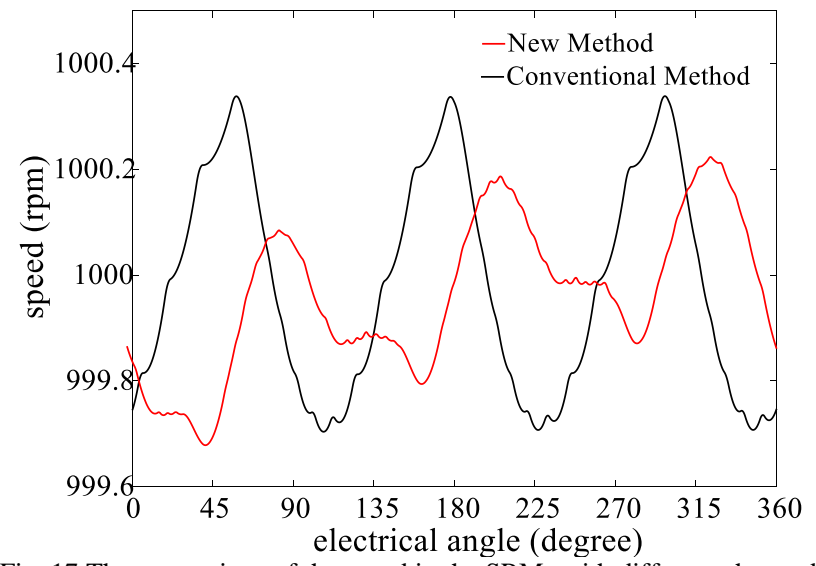

Fig. 17 The comparison of the speed in the SRMs with different phases driven by different methods
Fig. 17 shows the comparison of the speeds between the two different driving methods. It can be seen that the speed ripple generated by the new method is much lower than the conventional method. Because the new method generates a smoother commutation of winding currents, the speed ripple decreases and the speed waveform is smoother than for the conventional driving method.

Compared to the conventional method, Fig. 16 and Fig. 17 show that the new method can reduce the torque ripple and speed ripple in the SRM, because a smoother commutation of winding currents is generated by it than the conventional method.

\section{INFLUENCE ON THE POWER RATING AND LOSSES}

The input power of the SRM can be divided into two parts, the first part is the power for output torque $i^{2} \frac{d L}{d \theta} \omega$, the second part is the storage power in the windings $\frac{d}{d t}\left(\frac{1}{2} L i^{2}\right)[19]$. In the conventional driving method, because of the external diode structure, only the first part power generates the torque [20] . In the new method, however, because of the ring structure, the storage power in the windings can also contribute to the torque production. As a result, the output power difference between the two driving methods is $\frac{d}{d t}\left(\frac{1}{2} L i^{2}\right)$, which means that the new method has a higher power rating than the conventional method.

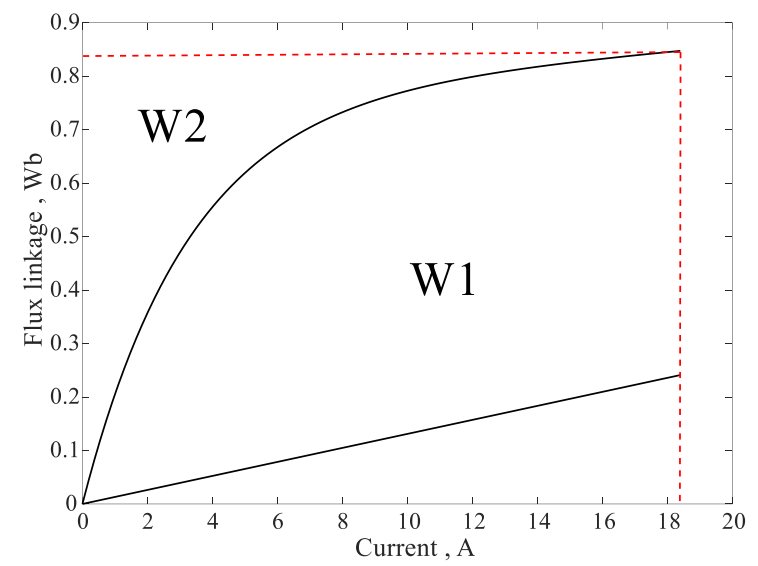

Fig. 18 The relation between magnetic field energy storage and mechanical energy

As can be found in Fig. 18, in the conventional method, the mechanical energy can be described as the area of W1, the magnetic field energy storage can be described as the area of W2. We assume the power rating as $P_{r}$, the power stored in the winding as $P_{w}$.

In the new method, by the ring structure and windings connected in series, W2 in one winding is transferred to the other two windings, which will contribute to the torque production. As a result, the power rating increases to $P_{r}+P_{w}$.

On the other hand, because of the additional DC-DC converter, the losses in the new method are supposed to be higher than in the conventional method. 

is

The conduction loss of the IGBT with the freewheel diode

$$
P_{\text {conduction }}=V_{d} I_{d} D N_{p}
$$

Where $V_{d}$ is the voltage drop in the IGBT with the diode, $I_{d}$ is the conduction current in the IGBT with the reverse recovery diode, and $D$ is the ratio of the current conduction period in one cycle period, $N_{p}$ is the phase number.

The switching loss of the IGBT can be calculated as:

$$
P_{\text {switch }}=\left(E_{\text {on }}+E_{\text {off }}\right) f_{\text {switch }}
$$

Where $E_{\text {on }}$ is the loss in a single turn-on pulse, $E_{\text {off }}$ is the loss in a single turn-off pulse of the IGBT, $f_{\text {switch }}$ is the frequency of the PWM wave.

The switching loss of the reverse recovery diode can be calculated as:

$$
P_{\text {diodeswitch }}=E_{r r} f_{\text {switch }}
$$

Where $E_{r r}$ is the loss in a single turn-off pulse of the diode.

With the speed of 1000rpm and load of $6 \mathrm{~N}^{*} \mathrm{~m}$, based on the datasheet of the IGBT and diode, the parameters for the loss calculation are shown in TABLE I.

TABLE I

THE PARAMETERS FOR THE LOSS CALCULATION

\begin{tabular}{cccc}
\hline \hline & & \multicolumn{2}{c}{ Proposed Method } \\
Parameters & Conventional Method & $\begin{array}{c}\text { 3-phase } \\
\text { inverter }\end{array}$ & $\begin{array}{c}\text { DC-DC } \\
\text { converter }\end{array}$ \\
\hline$E_{\text {on }}(\mathrm{mJ})$ & 5.5 & 5.5 & 5.5 \\
$E_{\text {off }}(\mathrm{mJ})$ & 4.5 & 4.5 & 4.5 \\
$f_{\text {swich }}(\mathrm{Hz})$ & 5000 & 5000 & 5000 \\
$E_{r r}(\mathrm{~mJ})$ & 3.8 & 3.8 & 3.8 \\
$V_{d}(\mathrm{~V})$ & 1 & 1 & 1 \\
$I_{d}(\mathrm{~A})$ & 8 & 7 & 4.5 \\
$D$ & $1 / 3$ & $2 / 3$ & 1 \\
$N_{p}$ & 3 & 3 & 1 \\
\hline \hline
\end{tabular}

In the three-phase inverter of the proposed method, for each leg, there is only one IGBT that works simultaneously. In the DC-DC converter, only one IGBT works at the moment.

In the conventional method, for each leg of the three-phase inverter, there are two IGBTs work simultaneously.

The results of the losses in different driving methods are shown in TABLE II.

TABLE II THE RESULTS OF THE LOSSES IN DIFFERENT DRIVING METHODS

\begin{tabular}{cccc}
\hline \multirow{2}{*}{ Type } & $\begin{array}{c}\text { Conventional } \\
\text { Method }\end{array}$ & $\begin{array}{c}\text { 3-phase } \\
\text { inverter }\end{array}$ & $\begin{array}{c}\text { DC-DC } \\
\text { converter }\end{array}$ \\
\hline Conduction Losses & $16 \mathrm{~W}$ & $14 \mathrm{~W}$ & $4.5 \mathrm{~W}$ \\
Switching Losses & $138 \mathrm{~W}$ & $138 \mathrm{~W}$ & $69 \mathrm{~W}$ \\
Total Losses & $154 \mathrm{~W}$ & & $225.5 \mathrm{~W}$ \\
\hline \hline
\end{tabular}

Based on the conclusion above, the total losses of the proposed method are $46.4 \%$ higher than the conventional method.

From TABLE II, it can be observed that the proposed method has higher losses than the conventional method, of which the reason is that compared to the conventional method, the proposed method has an additional power supply system (DC-DC converter) that generates the required circulating current. The DC-DC converter contains semiconductor components that contribute to the extra switching losses and conduction losses.

In order to deal with the extra power losses, a solution is to optimize the semiconductor components in the DC-DC converter. It is known that compared to the standard silicon diode, the $\mathrm{SiC}$ (silicon carbide) diode has lower switching losses and lower forward voltage drop, besides the $\mathrm{SiC}$ diode, the MOSFET also requires less power to be controlled and has lower conduction resistance than the standard silicon diode. As a result, the power losses in the proposed method can be improved by using $\mathrm{SiC}$ diode, at the same time, synchronous rectification can also be used to reduce the losses by using MOSFET.

\section{VALIDATION}

A three-phase SRM is chosen for experimental testing. The characteristics of the practical SRM are described in Fig. 5. Apart from the prototype SRM, the whole driving system consists of a load machine with torque sensors, a conventional inverter box, three current sensors, three position sensors, a DC power supply, a DC-DC buck circuit, a DSPACE 1103 controller board, and a PC with DSPACE 1103 blocks installed. The practical system is shown in Fig. 19.

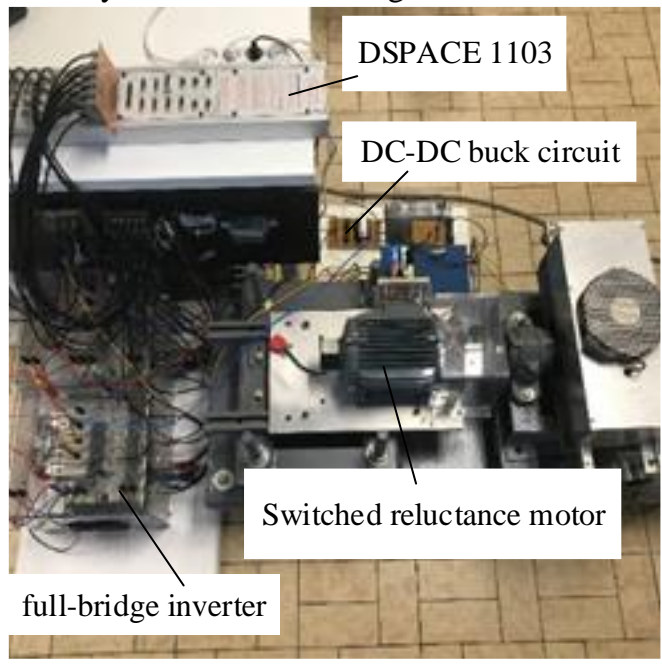

Fig. 19 The setup of the SRM control system

With different reference values of speed and load, we make the comparison of the winding currents between the conventional method and the new method to analyze the difference and the improvement. At the same time, the comparison of leg currents is also made between the practical result and the simulation result.

Fig. 20 shows the comparison of the winding currents between the new method and the conventional method, at a reference speed of $1000 \mathrm{rpm}$ and a load of $6 \mathrm{~N}^{*} \mathrm{~m}$. 


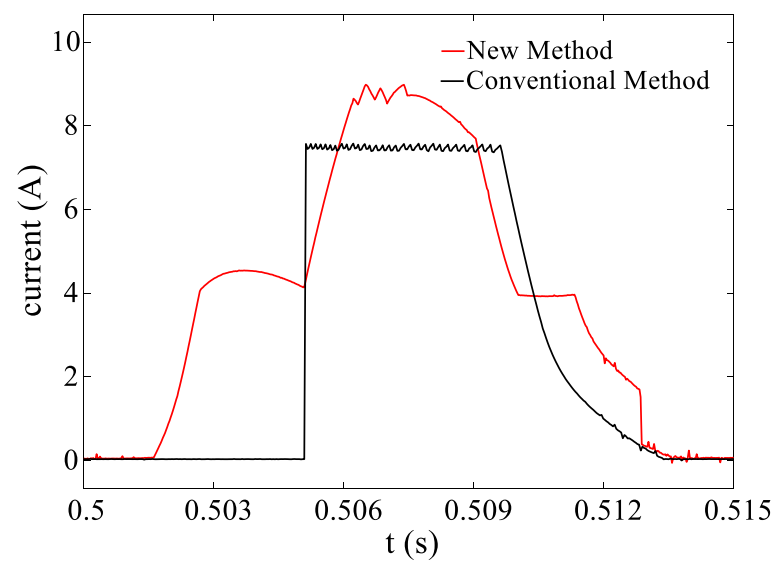

Fig. 20 The comparison of the winding currents between different methods at $1000 \mathrm{rpm}$ and $6 \mathrm{~N}^{*} \mathrm{~m}$ load

It can be found in Fig. 20 that with the new method, the winding current has a trapezoidal waveform, while with the conventional method, the waveform is rectangle. Because of the additional DC voltage source, the amplitude of the winding current in the new method is a bit higher than in the conventional method, and because of their same on and off angles, the frequency of the currents is the same [21] .

Fig. 21 shows the comparison of the leg current in the inverter between simulation and validation results at the speed of 1000rpm and load of $6 \mathrm{~N}^{*} \mathrm{~m}$.

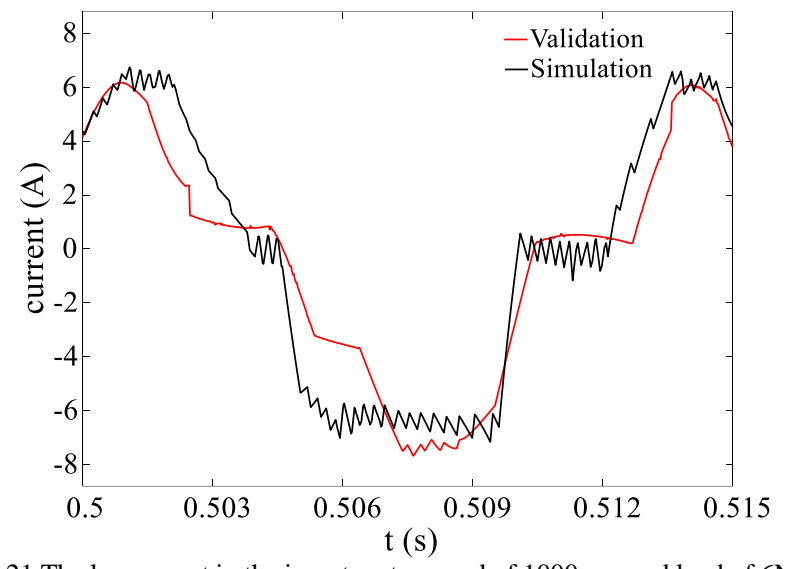

Fig. 21 The leg current in the inverter at a speed of 1000rpm and load of $6 \mathrm{~N}^{*} \mathrm{~m}$

From the comparison shown in Fig. 21, it can be seen that the measured results match well with the simulated ones, the inverter generates trapezoidal current waveform to drive the SRM.

From Fig. 20 and Fig. 21 it can be found that the winding current and the leg current waveforms are asymmetric and unbalanced. The PI controller is one of the reasons that the winding current and the leg current are not balanced. The circulating current is controlled and regulated by the PI controller and the DC-DC converter, as a result, the winding current cannot follow the reference value without error.

Another reason is the additional voltage source (DC-DC converter). In order to maintain the winding current positive, the additional power supply is inserted. If the diode current gets some moment negative, it introduces some lower harmonics in the winding and leg currents. Because the output voltage of the
DC-DC converter contains the inevitable harmonics and low frequency ripple, the winding current is asymmetric and unbalanced, so is the leg current.

With a higher reference speed (1300rpm) and the same load $\left(6 \mathrm{~N}^{*} \mathrm{~m}\right)$, the comparison of different currents is shown in Fig. 22 to Fig. 23.

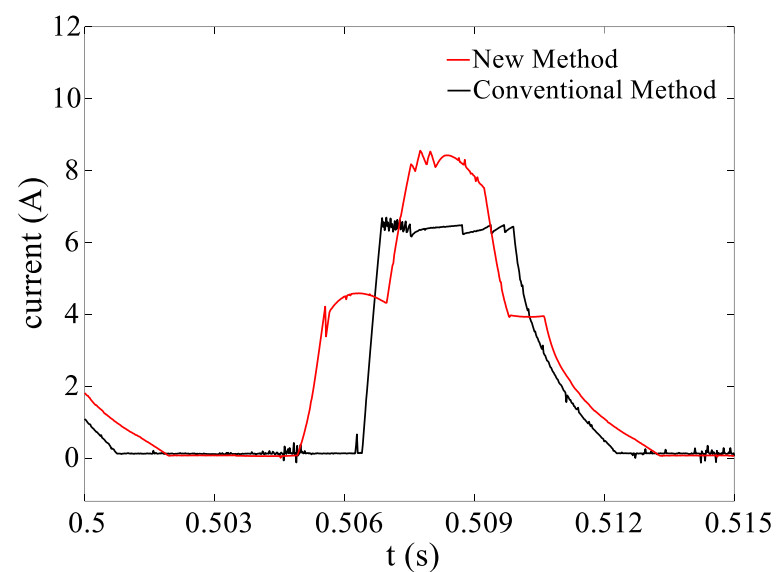

Fig. 22 The comparison of the winding currents between different methods at speed of 1300rpm and load of $6 \mathrm{~N}^{*} \mathrm{~m}$

Fig. 22 shows the difference of the winding current between the new method and the conventional method. It can be found that with a higher speed, the frequency of the winding current increases with both of the methods, but the amplitude does not change [22] .

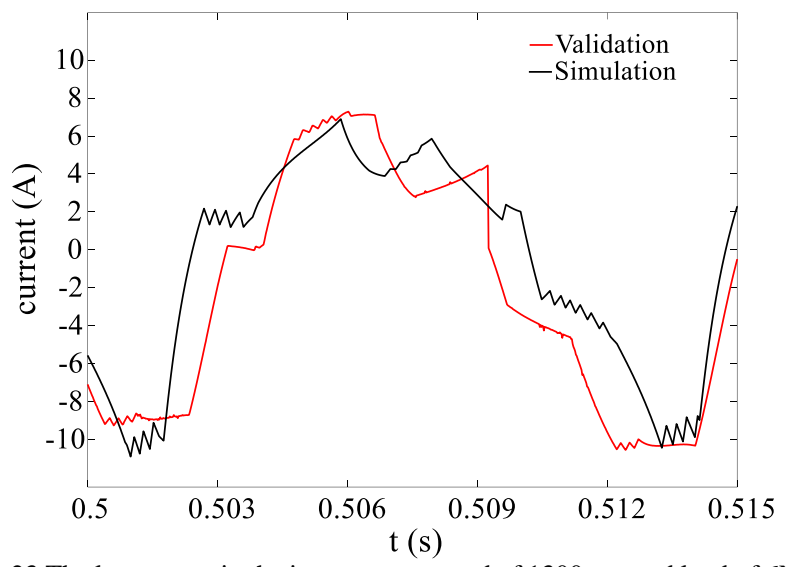

Fig. 23 The leg current in the inverter at a speed of $1300 \mathrm{rpm}$ and load of $6 \mathrm{~N}^{*} \mathrm{~m}$

From Fig. 23 it can also be found that the frequency of the leg current increases because of the higher speed, at the same time, a good agreement with the theoretical analysis can still be observed for both of the measured results and simulated results.

A higher load $\left(8 \mathrm{~N}^{*} \mathrm{~m}\right)$ is applied in the SRM system, at a reference speed of 1000rpm. The comparison of different currents is shown in Fig. 24 and Fig. 25. 


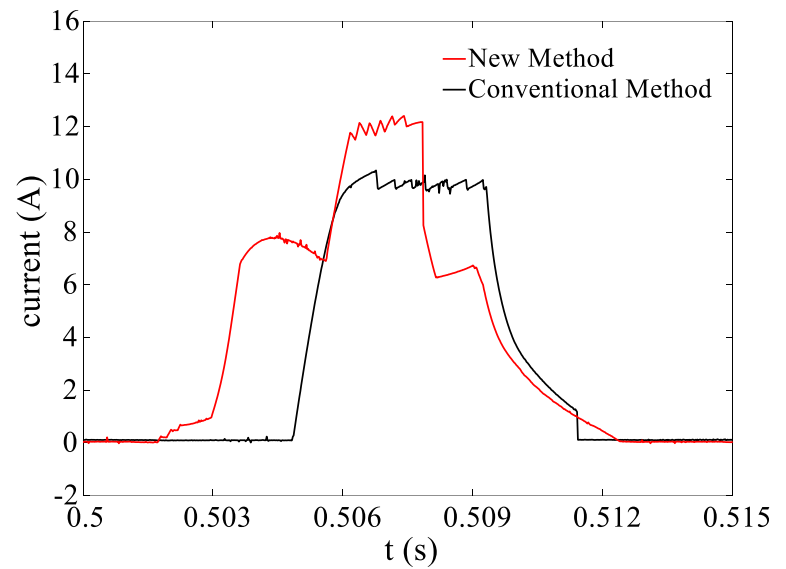

Fig. 24 The comparison of the winding currents between different methods at speed of 1000rpm and load of $8 \mathrm{~N}^{*} \mathrm{~m}$

Compared to Fig. 20, Fig. 24 shows that with a higher load of $8 \mathrm{~N} * \mathrm{~m}$ instead of $6 \mathrm{~N} * \mathrm{~m}$, the amplitude of the winding currents generated by both of the methods increases. Because of (3), the winding current has to increase to generate a higher torque [23] . At the same time, because the speed remains $1000 \mathrm{rpm}$, the frequency of the winding currents stays the same: see Fig. 20.

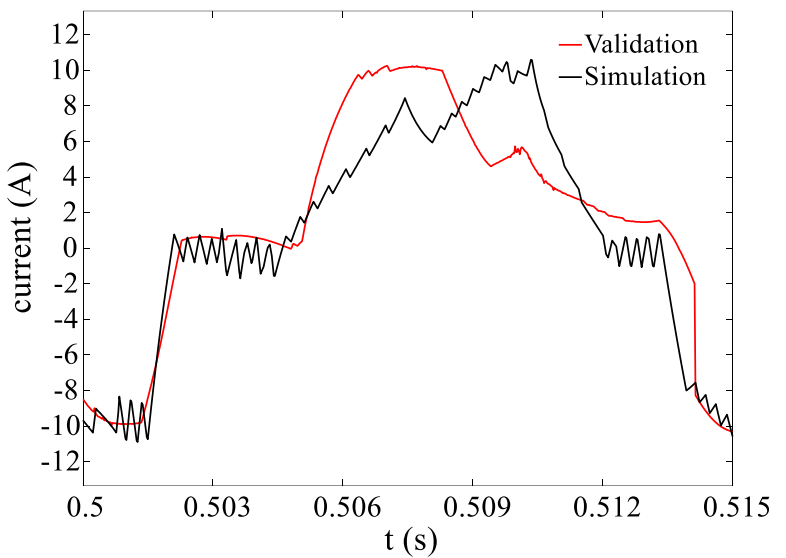

Fig. 25 The leg current in the inverter at a speed of 1000rpm and load of $8 \mathrm{~N} * \mathrm{~m}$

The leg current shown in Fig. 25 also explains that besides the increasing amplitude and constant frequency of the leg current, both of the simulated results and measured results have the same trend as the theoretical prediction.

The validation indicates that with the new structure, the SRM can be driven by the new method. The theoretical analysis can be verified by the practical system. For different speeds and loads, the measured results correspond to the simulated results.

\section{CONCLUSION}

A novel method for driving SRM has been proposed. With a ring structure, a SRM can be driven by a standard full bridge inverter.

The topology and the operating principle of the new method are proposed. The range of the circulating current is calculated based on the vector operation. The versatility for the SRMs with four and five phases is then described. Based on the principle for the SRM with three phases, the theory of the new method is verified to be applied to the SRMs with different numbers of phases.

Based on the current analysis, the comparison between the conventional method and the new method is made by using the simulation tool. The impact of the new method on the power rating and losses is also analyzed. Based on the analysis, it proves that the new method can reduce the torque ripple and speed ripple in SRMs, it can also improve the power rating of the SRM. The losses, however, are increased because of the additional DC-DC converter, which can be improved by optimizing the semiconductor components in the DC-DC converter.

With the DSPACE platform and three-phase SRM prototype, the conventional method and the new method are compared in the practical system for different speeds and loads. The measured results are also compared with the simulated results. As a result, the theoretical analysis of the proposed idea is verified by validation, and the measured data matches the simulated data well.

In conclusion, the new method for driving SRM is verified by simulation and validation. The new method can be applied to different types of SRM, and it can also improve the performance of the SRM. This makes it possible to drive a SRM by using a standard full-bridge inverter and an extra ring structure. Besides no adverse influence on the performance of the SRMs, the new method has the advantage to improve the power rating of the SRMs. Compared with other driving methods, the proposed method achieves less cost and higher power rating, which makes it competitive.

\section{REFERENCES}

[1] Kim, J.H. and Kim, R.Y., 2018. Sensorless direct torque control using the inductance inflection point for a switched reluctance motor. IEEE Transactions on Industrial Electronics, 65(12), pp.9336-9345.

[2] Fang, J., Li, W., Li, H. and Xu, X., 2015. Online inverter fault diagnosis of buck-converter BLDC motor combinations. IEEE Transactions on Power Electronics, 30(5), pp.2674-2688.

[3] Rocha, N., de Oliveira, Í.A.C., de Menezes, E.C., Jacobina, C.B. and Dias, J.A.A., 2016. Single-phase to three-phase converters with two parallel single-phase rectifiers and reduced switch count. IEEE Transactions on Power Electronics, 31(5), pp.3704-3716.

[4] X. Y. Ma, G. J. Li, G. W. Jewell, Z. Q. Zhu and H. L. Zhan, "Performance Comparison of Doubly Salient Reluctance Machine Topologies Supplied by Sinewave Currents," in IEEE Transactions on Industrial Electronics, vol. 63, no. 7, pp. 4086-4096, July 2016.

[5] C. Gan, J. Wu, Y. Hu, S. Yang, W. Cao and J. M. Guerrero, "New Integrated Multilevel Converter for Switched Reluctance Motor Drives in Plug-in Hybrid Electric Vehicles With Flexible Energy Conversion," in IEEE Transactions on Power Electronics, vol. 32, no. 5, pp. 3754-3766, May 2017.

[6] A.N. Shishkov, E.V. Belousov, M.A. Grigoryev, Traction Electric Drive with the Field Regulated Reluctance Machine, Procedia Engineering,vol. 129, 2015, pp. 940-945.

[7] J. D. Law, A. Chertok and T. A. Lipo, "Design and performance of field regulated reluctance machine," in IEEE Transactions on Industry Applications, vol. 30, no. 5, pp. 1185-1192, Sept.-Oct. 1994.

[8] M. Takano and S. Shimomura, "Study of variable reluctance vernier motor for hybrid electric vehicle," 2013 IEEE ECCE Asia Downunder, Melbourne, VIC, 2013, pp. 1341-1347.

[9] R. Marlow, N. Schofield and A. Emadi, "A Continuous Toroidal Winding SRM With 6- or 12-Switch DC Converter," in IEEE Transactions on Industry Applications, vol. 52, no. 1, pp. 189-198, Jan.-Feb. 2016.

[10] G. K. Ptakh, N. F. Evsin, D. A. Zvezdunov, D. V. Rozhkov and A. E. Yakovenko, "Switched reluctance motor for electric drive of overland belt 
conveyor," 2014 17th International Conference on Electrical Machines and Systems (ICEMS), Hangzhou, 2014, pp. 1817-1821.

[11] C. Shi, J. Qiu and R. Lin, "A Novel Self-Commutating Low-Speed Reluctance Motor for Direct-Drive Applications," in IEEE Transactions on Industry Applications, vol. 43, no. 1, pp. 57-65, Jan.-Feb. 2007.

[12] Sun, H., Farzan Moghaddam, A., Hussein Mohamed, A., Nabil Ibrahim, M., Sergeant, P., \& Van den Bossche, A. (2018). Controlling a Switched Reluctance Motor with a Conventional Three-Phase Bridge Instead of Asymmetric H-Bridges. Energies, 11(12), 3242.

[13] H. Sun et al., "A Control Method with Ring Structure for Switched Reluctance Motor," 2018 IEEE International Conference on Electrical Systems for Aircraft, Railway, Ship Propulsion and Road Vehicles \& International Transportation Electrification Conference (ESARS-ITEC), Nottingham, 2018, pp. 1-5.

[14] Ding, W., Yang, S. and Hu, Y., 2019. Performance Improvement for Segmented-Stator Hybrid-Excitation SRM Drives Using an Improved Asymmetric Half-Bridge Converter. IEEE Transactions on Industrial Electronics, 66(2), pp.898-909.

[15] Liu, K., Hou, C. and Hua, W., 2019. A Novel Inertia Identification Method and Its Application in PI Controllers of PMSM Drives. IEEE Access.

[16] Song, S., Xia, Z., Fang, G., Ma, R. and Liu, W., 2018. Phase Current Reconstruction and Control of Three-Phase Switched Reluctance Machine with Modular Power Converter Using Single DC-Link Current Sensor. IEEE Transactions on Power Electronics, 33(10), pp.8637-8649.

[17] Xie, L., Ruan, X. and Ye, Z., 2018. Reducing common mode noise in phase-shifted full-bridge converter. IEEE Transactions on Industrial Electronics, 65(10), pp.7866-7877.

[18] F. J. T. E. Ferreira, A. M. Silva, S. M. A. Cruz and A. T. De Almeida, "Comparison of losses in star- and delta-connected induction motors with saturated core," 2017 IEEE International Electric Machines and Drives Conference (IEMDC), Miami, FL, 2017, pp. 1-8.

[19] Bao, J., Boynov, K., Paulides, J. and Lomonova, E., 2016. Usage of the inductive energy storage in the field winding for driving the variable reluctance motor. IEEE Transactions on Magnetics, 52(7), pp.1-4.

[20] Li, G., Zhu, Z.Q., Ma, X.Y. and Jewell, G.W., 2016. Comparative Study of Torque Production in Conventional and Mutually Coupled SRMs Using Frozen Permeability. IEEE Transactions on Magnetics, 52(6).

[21] J. Dexter, L. Huang, Z. Q. Zhu and X. Vinamata, "Comparison of Frequency and Time Domain Based Current Profiling Techniques for Acoustic Noise Reduction in Switched Reluctance Machine," 2018 21st International Conference on Electrical Machines and Systems (ICEMS), Jeju, 2018, pp. 1908-1913.

[22] Ofori, E., Husain, T., Sozer, Y. and Husain, I., 2015. A pulse-injectionbased sensorless position estimation method for a switched reluctance machine over a wide speed range. IEEE Transactions on Industry Applications, 51(5), pp.3867-3876.

[23] Tousizadeh, M., Che, H.S., Selvaraj, J., Rahim, N.A. and Ooi, B.T., 2019. Performance comparison of fault-tolerant three-phase induction motor drives considering current and voltage limits. IEEE Transactions on Industrial Electronics, 66(4), pp.2639-2648.

\section{BIOGRAPHIES}

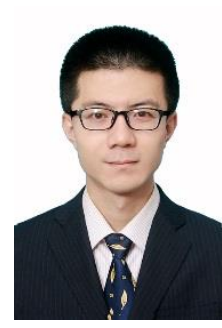

Haitao Sun was born in China in 1989. He received the B.Sc. degree in automation and the M.Sc. degree in electrical engineering from Taiyuan University of Technology, Taiyuan, China, in 2012 and 2016 respectively. Since 2016, he has been working toward the Ph.D. degree in the Department of Electrical Energy, Metals, Mechanical Constructions and Systems, Ghent University, Gent, Belgium. His research interests include power electronics, electrical drives, motor analysis and design, switched reluctance machine, control theory, and

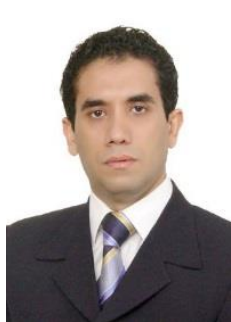

Ali Farzan Moghaddam was born in Tehran in Iran, on June 22,1979. He graduated from the technical high school, Tehran. He studied at Beheshti college and received his associate degree in Electrical Engineering. $\mathrm{He}$ received his B.Sc. degree from Azad University (South Branch) in Electrical Engineering. In 2010 he graduated from Eastern Mediterranean University (EMU) and received his M.Sc. degree in Electrical and Electronic Engineering. He worked as a research assistant in Eastern Mediterranean University from (2008-2010). His employment experience included the Arian company, Tehran, Iran (2010- 2015). His special field of interest included power electronics, Battery Management system (BMS) for Electrical Vehicles in passive and active balancing techniques. In 2015 he started his $\mathrm{PhD}$ in Department of Electrical Energy at Ghent University, Gent, Belgium. Currently his research interest include Battery Management System for Electrical Vehicles (Active Cell Balancing Method).

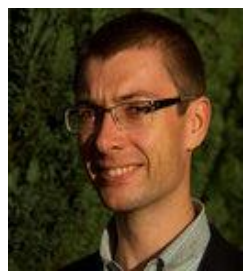

Peter Sergeant received the M.Sc. degree in electromechanical engineering and the Ph.D. degree in engineering sciences from Ghent University, Ghent, Belgium, in 2001 and 2006, respectively. In 2001, he became a Researcher at the Electrical Energy Laboratory, Ghent University. $\mathrm{He}$ became a Postdoctoral Researcher at Ghent University in 2006 (Postdoctoral Fellow of the Research FoundationFlanders) and at Ghent University College in 2008 Since 2012, he has been an Associate Professor at Ghent University. His current research interests include numerical methods in combination with optimization techniques to design nonlinear electromagnetic systems, in particular, electrical machines for sustainable energy applications.

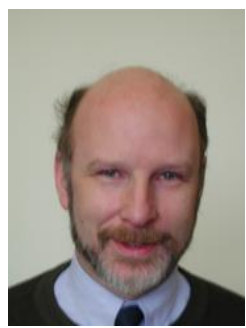

Alex Van den Bossche received his $\mathrm{MSc}$ and $\mathrm{PhD}$ degrees in electromechanical engineering from Ghent University Belgium in 1980 and 1990, respectively. He has worked at the university's Electrical Energy Laboratory since 1993 . He is a professor at the same university in the same field. His research is in the field of electrical drives, power electronics on various inverter types and passive components, and magnetic materials. $\mathrm{He}$ is also interested in renewable energy conversion. $\mathrm{He}$ is the author of the book entitled Inductors and Transformers for Power Electronics. He has started two spin-off companies. 